\title{
THE NECESSARY AND SUFFICIENT CONDITIONS FOR GENERAL HADAMARD PRODUCT OF CLASSES OF ANALYTIC FUNCTIONS
}

\author{
LIANGPENG XiONG
}

Abstract. Let $P_{a}(A, B)$ be the classes of analytic functions $f(z)$, where $f(z) \prec \frac{a+A z}{1-B z}, A+a B \neq 0$ and $|B| \leqslant 1$. For classes $\mathscr{H}_{1}, \mathscr{H}_{2}, \cdots, \mathscr{H}_{n}$ of analytic functions, we define the general hadamard product of the form $\mathscr{H}_{1} *_{m_{1}} \mathscr{H}_{2} *_{m_{2}} \mathscr{H}_{3} * \cdots *_{m_{n-1}} \mathscr{H}_{n}(z)=\left\{f_{1} *_{m_{1}} f_{2} *_{m_{2}} f_{3} * \cdots *_{m_{n-1}} f_{n}(z):\right.$ $\left.f_{i} \in \mathscr{H}_{i}, i=1,2, \ldots, n, n \in \mathbb{Z}^{+}, m_{i} \in \mathbb{C}\right\}$. In this paper, we discuss the conditions for equality $P_{a_{1}}\left(A_{1}, B_{1}\right) *_{m_{1}} P_{a_{2}}\left(A_{2}, B_{2}\right) * \cdots *_{m_{n-1}} P_{a_{n}}\left(A_{n}, B_{n}\right)=P_{c}(X, Y)$. Some consequences of the main results for known classes of analytic functions are also pointed out.

Mathematics subject classification (2010): 30C45, 30C50.

Keywords and phrases: Analytic function, Hadamard product, subordination, geometric function.

\section{REFERENCES}

[1] M. ARIF, K. I. Noor, M. RAZA, W. HAQ, Some properties of a generalized class of analytic functions related with janowski functions, Abstract and applied analysis 2012, 1, (2012), 1-11.

[2] S. P. Goyal, Pranay Goswami, On certain properties for a subclass of close-to Cconvex functions, Journal of classical analysis 1, 2, (2012), 103-112.

[3] M. K. Aouf, The Quasi-Hadamard product of certain analytic functions, Appl. Math. Lett. 21, 11, (2008), 1184-1187.

[4] H. E. DARWish, M. K. Aouf, Generalizations of modified-Hadamard products of p-valent functions with negative coefficients, Math. Comput. Modelling 49, 1-2, (2009), 38-45.

[5] R. M. Goel, B. S. Mehrok, A subclass of univalent functions, Austral. Math. Soc. (Ser. A) 35, 1, (1983), 1-17.

[6] D. J. HALLENBECK, Linear problems and convexity techniques in geometric function theorem, Pitman Advanced Publishing Program, Boston, (1984).

[7] W. Janows Ki, Some extremal problems for certain families of analytic functions, Ann. Polon. Math 28, 2, (1973), 297-326.

[8] Y. Komatu, On convolution of power series, Kodai Math. Sem. Rep. 19, 3, (1958), 141-144.

[9] R. R. LONDON, A convolution theorem for functions mapping the unit disc into half planes, Math. Japonica. 43, 1, (1996), 23-29.

[10] Z. Nehari, E. Netanyahu, On the coefficients of meromorphic functions, Proc. Amer. Math. Soc. 8, 1, (1957), 15-23.

[11] K. PIEJKo, On some convolution theorems, Comment. Math. Prace Mat. 42, 1, (2002), 103-112.

[12] K. PIEJKo, Hadamard product of certain classes of functions, J. Appl. Anal. 11, 1, (2005), 145-151.

[13] K. PIEJKO, Generalized convolutions and classes of functions defined by subordination, Computers and Mathematics with Applications 57, 3, (2009), 302-307.

[14] H. M. Srivastava, S. Owa, S. K. ChatterJe, A note on certain classes of starlike functions, Rend. Sem. Mat. Univ. Padova 77, 2, (1987), 115-124.

[15] J. SoKóŁ, On a condition for $\alpha$-starlikeness, J. Math. Anal. Appl 352, 2, (2009), 696-701.

[16] J. Stankiewicz, Z. StankiEwicz, Convolution of some classes of function, Folia. Sci. Univ. Tech. Resov. Math. 7, 1, (1988), 93-101.

[17] L. P. XIONG, Some general results and extreme points of p-valent functions with negative coefficients, Demonstratio Mathematica 44, 2, (2011), 261-272. 
[18] LiangPeng Xiong, Xiaoli LiU, Hadamard product of finitely order of certain class of analytic functions defined by subordination, Acta Mathematica Scientia 34(A), 1, (2014), 150-156 (In Chinese). 